\title{
Resuscitative retrograde blood cardioplegia
}

\author{
Are amino acids or continuous warm techniques necessary?
}

This experiment was designed to determine the relative degree of cardiac functional recovery provided by various forms of resuscitative retrograde blood cardioplegia after global ischemic injury. Twenty-four dogs were subjected to 20 minutes of normothermic global myocardial ischemia followed by 60 minutes of cardioplegic arrest by one of three methods: group 1, standard cold blood cardioplegia with a cold terminal dose $(n=8)$; group 2, aspartate-glutamate-enhanced blood cardioplegia with warm induction and terminal enhancement $(n=8)$; and group 3, continuous warm blood cardioplegia $(n=8)$. Sonomicrometry was used to analyze left ventricular function for maximal elastance and preload recruitable stroke work area. Data were recorded at baseline and after 30 and 60 minutes of unloaded reperfusion. The results showed improved early recovery of preload recruitable stroke work area, but not of maximal elastance, after reperfusion of ischemic hearts with warm resuscitative blood cardioplegic solution enhanced with amino acids. The functional improvement provided by this technique was transient, however, and no significant differences were detectable among the groups after 60 minutes of unloaded reperfusion. Neither amino acid enhancement nor continuous warm cardioplegia offered a significant advantage in functional recovery over the standard method of cold blood cardioplegia reperfusion. (J THORAC CaRdIOvasC SuRg 1995;109:242-8)

Tohru Asai, MD, Eugene A. Grossi, MD, Martin LeBoutillier III, MD, Michael A. Parish, MD, F. Gregory Baumann, PhD, Frank C. Spencer, MD, Stephen B. Colvin, MD, and Aubrey C. Galloway, MD, New York, N.Y.

$\mathrm{R}$ ecent experimental data from our laboratory have shown that infusion of warm cardioplegic solution enhanced with amino acids provides no additional benefit for routine myocardial protection, even with prolonged aortic crossclamp times. ${ }^{1}$ Prior studies have also demonstrated nearly total myocardial functional recovery after aortic crossclamp times of 2 to 4 hours when multidose cold blood potassium cardioplegic solution was used. ${ }^{2}$ Myocardial protection for most patients, therefore, should

From the Division of Cardiothoracic Surgery, Department of Surgery, New York University Medical Center, New York, N.Y.

Read at the Nineteenth Annual Meeting of The Western Thoracic Surgical Association, Carlsbad, Calif., June 23-27, 1993.

Address for reprints: Aubrey C. Galloway, MD, Director of Surgical Research, New York University Medical Center, 530 First Ave., Suite 6D, New York, NY 10016.

Copyright (C) 1995 by Mosby-Year Book, Inc.

$0022-5223 / 95 \$ 3.00+0 \quad \mathbf{1 2 / 6 / 6 0 8 0 3}$ focus on providing good distribution of cardioplegic solution with uniform myocardial cooling.

In contrast, several reports based on ischemic injury models have noted improved recovery of cardiac function after the use of warm cardioplegic solution enhanced with amino acids. ${ }^{3-8}$ The investigators theorized that the addition of amino acids to the reperfusate of ischemic myocardium provides supplemental substrates to hasten recovery of myocardial high-energy phosphates and that the warm temperature contributes to optimal myocardial enzyme function, oxygen extraction, and repayment of oxygen debt. ${ }^{3-5,9}$ In addition, some investigators have recently suggested that warm continuous cardioplegia may be beneficial to the damaged heart, ${ }^{10-13}$ and this technique has been recommended for high-risk patients with ongoing ischemia or cardiogenic shock. In view of these recent recommendations, this experiment was designed to assess relative myocardial functional recovery after ischemic injury when these different clinical methods of 
Table I. Components of blood cardioplegic solution by group (final concentration on delivery to animal)

\begin{tabular}{|c|c|c|c|}
\hline & $\begin{array}{c}\text { Group 1: } \\
\text { Standard cold }\end{array}$ & $\begin{array}{c}\text { Group 2: } \\
\text { Amino acids }\end{array}$ & $\begin{array}{c}\text { Group 3: } \\
\text { Fremes' solution }\end{array}$ \\
\hline $5 \%$ Dextrose in $0.2 \%$ saline & $500 \mathrm{ml}$ & & \\
\hline $5 \%$ Dextrose in water & & $200 \mathrm{ml}$ & $500 \mathrm{ml}$ \\
\hline \multicolumn{4}{|l|}{ Potassium } \\
\hline High $(20-24 \mathrm{mEq} / \mathrm{L})$ & $100 \mathrm{mEq}$ & $100 \mathrm{mEq}$ & $50 \mathrm{mEq}$ \\
\hline Low $(8-12 \mathrm{mEq} / \mathrm{L})$ & $.40 \mathrm{mEq}$ & $40 \mathrm{mEq}$ & $30 \mathrm{mEq}$ \\
\hline Magnesium sulfate $(3-4 \mathrm{mEq} / \mathrm{L})$ & & & $9 \mathrm{mEq}$ \\
\hline THAM (pH 7.6) & $200 \mathrm{ml}$ & $200 \mathrm{ml}$ & $20 \mathrm{ml}$ \\
\hline $\mathrm{CPD}\left(0.4-0.6 \mathrm{mmol} / \mathrm{L} \mathrm{Ca}^{++}\right)$ & $200 \mathrm{ml}$ & $200 \mathrm{ml}$ & $10 \mathrm{ml}$ \\
\hline $50 \%$ Dextrose & $45 \mathrm{ml}$ & $45 \mathrm{ml}$ & \\
\hline Aspartate & & $9.81 \mathrm{gm}(13 \mathrm{mmol} / \mathrm{L})$ & \\
\hline Glutamate & & $10.69 \mathrm{gm}(13 \mathrm{mmol} / \mathrm{L})$ & \\
\hline Amino acid solution in water & & $250 \mathrm{ml}$ & r \\
\hline Osmolarity & $>400 \mathrm{mOsm}$ & $>400 \mathrm{mOsm}$ & $>400 \mathrm{mOsm}$ \\
\hline
\end{tabular}

THAM, Tromethamine; $C P D$, citrate-phosphate-dextrose.

retrograde resuscitative cardioplegia are used as adjuncts to left ventricular (LV) unloading during reperfusion.

\section{Materials and methods}

Preparation. Twenty-four heartworm-free adult mongrel dogs ( 25 to $30 \mathrm{~kg}$ ) were anesthetized with metocurine iodide (Metubine, $0.5 \mathrm{mg} / \mathrm{kg}$ ) and $\alpha$-chloralose $(100 \mathrm{mg} /$ $\mathrm{kg}$ ), intubated, and supported with a mechanical ventilator (Harvard Apparatus Co., Dover, Mass.). All animals received humane care in compliance with the "Principles of Laboratory Animal Care" formulated by the National Society for Medical Research and the "Guide for the Care and Use of Laboratory Animals" prepared by the Institute of Laboratory Animal Resources and published by the National Institutes of Health (NIH publication No. 86-23, revised 1985). The femoral artery and vein were instrumented for pressure tracings; arterial blood gases and serum electrolytes were monitored and kept within physiologic range during the entire procedure.

Experimental protocol. A median sternotomy was performed, the azygos vein ligated, and the pericardium fashioned into a cradle. The major and minor ventricular axes and wall thickness of the LV were instrumented with two pairs of piezoelectric crystals (Triton Technology, San Diego, Calif.), as previously described. ${ }^{1}$ A transmural needle biopsy was taken from the LV for ultrastructure evaluation, and an LV pressure catheter (Millar Instruments, Inc., Houston, Tex.), as well as a ventricular vent, was placed via the LV apex. The sinus node was excised and the right atrium was paced at a rate of $150 \mathrm{beats} / \mathrm{min}$. Total cardiopulmonary bypass was established via the femoral artery with bicaval cannulation. Another arterial cannula was inserted into the main pulmonary artery for right heart bypass. For data collection the preparation was switched from total heart-lung bypass with the LV vented to a right heart bypass model with a fully working LV.

All animals were subjected to 20 minutes of normothermic global myocardial ischemia by crossclamping the aorta. The aortic root and ventricular chambers were vented during this time; all hearts fibrillated within several minutes. Concurrently, the right atrium was opened laterally through a vertical incision and a pursestring suture was placed around the coronary sinus. Immediately before the end of the 20 minutes of ischemia a coronary sinus cardioplegia catheter (Shiley, Inc., Irvine, Calif.) was placed in the coronary sinus and the pursestring suture was snared. Blood cardioplegic solution was injected by means of one of the three reperfusion methods described herein. After 60 minutes of protected arrest, the aorta was unclamped, the retrograde coronary sinus catheter was removed, and the hearts were defibrillated. Whole blood reperfusion proceeded for an additional hour, with the ventricles fully unloaded and not ejecting.

Functional data were obtained before ischemia and at 30 minutes and 60 minutes after unclamping. Blood volume was added to the left side of the heart to raise the $\mathrm{LV}$ end-diastolic pressure to approximately $22 \mathrm{~mm} \mathrm{Hg}$ and then withdrawn to create a series of pressure-volume loops. When the experiment had been completed, transmural myocardial specimens were obtained for water content and ultrastructure analysis.

Experimental groups. Animals were randomly placed into one of three cardioplegia groups, with eight animals per group: group 1, standard multidose cold blood cardioplegia with a cold terminal dose; group 2, aspartateglutamate-enhanced multidose cold blood cardioplegia, with warm induction and warm terminal enhancement injections; and group 3, continuous warm cardioplegia with Fremes' solution. ${ }^{12}$ The cardioplegic solutions in groups 1 and 2 were identical except for the presence of amino acid enhancement in group 2, whereas the composition of group 3 solution was slightly different (Table I). All groups received cardioplegic solution in retrograde fashion with flow rates of $100 \mathrm{ml} / \mathrm{min}$.

For groups 1 and 2 oxygenated blood was cooled to $4^{\circ} \mathrm{C}$ in a BCD Plus heat exchanger (Shiley) and mixed 4:1 with cardioplegic solution. In group 2 the cardioplegic solution was enhanced with both aspartate and glutamate in a concentration of $13 \mathrm{mmol} / \mathrm{L}$. Groups 1 and 2 received an initial dose of high-potassium cardioplegic solution (20 $\mathrm{ml} / \mathrm{kg}$ of 20 to $24 \mathrm{mEq} / \mathrm{L}$ ), with subsequent doses of low-potassium cardioplegic solution $(10 \mathrm{ml} / \mathrm{kg}$ of 8 to 12 
Table II. PRSW results by treatment group

\begin{tabular}{|c|c|c|c|}
\hline & \multicolumn{3}{|c|}{ Treatment groups } \\
\hline & Group 1 & Group 2 & Group 3 \\
\hline Preclamp slope $\left(\mathrm{erg} \times 10^{3} / \mathrm{ml}\right)$ & $153.1 \pm 15.9$ & $126.6 \pm 9.77$ & $153.3 \pm 9.31$ \\
\hline $30 \mathrm{~min}$ slope $\left(\mathrm{erg} \times 10^{3} / \mathrm{ml}\right)$ & $\begin{array}{c}68.3 \pm 11.7 \\
(46.3 \%)\end{array}$ & $\begin{array}{c}88.7 \pm 10.4^{*} \\
(69.7 \%)\end{array}$ & $\begin{array}{c}74.8 \pm 90.6 \\
(49.4 \%)\end{array}$ \\
\hline $60 \mathrm{~min}$ slope $\left(\operatorname{erg} \times 10^{3} / \mathrm{ml}\right)$ & $\begin{array}{c}76.6 \pm 17.9 \\
(48.9 \%)\end{array}$ & $\begin{array}{c}77.5 \pm 11.6 \\
(60.4 \%)\end{array}$ & $\begin{array}{c}85.8 \pm 18.0 \\
(56.4 \%)\end{array}$ \\
\hline Preclamp intercept (ml) & $16.6 \pm 2.8$ & $22.0 \pm 3.5$ & $14.2 \pm 2.4$ \\
\hline $30 \mathrm{~min}$ intercept $(\mathrm{ml})$ & $\begin{array}{c}27.4 \pm 4.25 \\
(171.2 \%)\end{array}$ & $\begin{array}{c}30.5 \pm 4.15 \\
(149.2 \%)\end{array}$ & $\begin{array}{c}23.9 \pm 4.69 \\
(165.2 \%)\end{array}$ \\
\hline $60 \mathrm{~min}$ intercept $(\mathrm{ml})$ & $\begin{array}{c}26.4 \pm 4.20 \\
(164.5 \%)\end{array}$ & $\begin{array}{c}31.5 \pm 4.42 \\
(153.1 \%)\end{array}$ & $\begin{array}{c}23.1 \pm 4.65 \\
(156.8 \%)\end{array}$ \\
\hline Preclamp PRWA & $54,299 \pm 12,839$ & $73,411 \pm 24,787$ & $76,325 \pm 20,742$ \\
\hline 30 min PRWA & $\begin{array}{c}7,321 \pm 1,061 \\
(17.7 \%)\end{array}$ & $\begin{array}{c}26,930 \pm 8,036^{*} \\
(43.4 \%)\end{array}$ & $\begin{array}{c}15,498 \pm 3,129 \\
(28.1 \%)\end{array}$ \\
\hline 60 min PRWA & $\begin{array}{c}8,797 \pm 1,312 \\
(25.7 \%)\end{array}$ & $\begin{array}{c}23,112 \pm 9,900 \\
(37.1 \%)\end{array}$ & $\begin{array}{c}16,802 \pm 2,983 \\
(38.3 \%)\end{array}$ \\
\hline
\end{tabular}

Values are absolute mean \pm standard error of the mean (percent change of mean from pre-crossclamping control value).

$* p<0.05$ by repeated-measures analysis of variance.

$\mathrm{mEq} / \mathrm{L}$ ) every 15 minutes. In group 1 all doses were given at $6^{\circ} \mathrm{C}$. For group 2 the first dose was initially given at $36^{\circ} \mathrm{C}(10 \mathrm{ml} / \mathrm{kg})$ and then switched to $6^{\circ} \mathrm{C}(10 \mathrm{ml} / \mathrm{kg})$, as were subsequent doses; the terminal dose was given at $36^{\circ} \mathrm{C}$. In group 3 cardioplegic solution was given continuously at $36^{\circ} \mathrm{C}$ to maintain a coronary sinus pressure of 35 to $45 \mathrm{~mm} \mathrm{Hg}$. Initially, high-potassium ( 20 to $24 \mathrm{mEq} / \mathrm{L}$ ) cardioplegic solution was used to arrest the heart, after which the solution was changed to a low potassium concentration ( 8 to $12 \mathrm{mEq} / \mathrm{L}$ ). In groups I and II the systemic perfusate was kept at $30^{\circ} \mathrm{C}$ until 15 minutes before unclamping, when it was warmed to $36^{\circ} \mathrm{C}$. In group 3 it was kept at $36^{\circ} \mathrm{C}$. In all groups the hematocrit value during bypass was between $20 \%$ and $26 \%$.

Ultrastructural examination. Ultrastructural examination was performed on transmural needle biopsy specimens of LV tissue obtained from each animal at baseline and after 60 minutes of reperfusion. These specimens were rapidly immersed in fresh, cold, $3 \%$ glutaraldehyde in Sorensen's phosphate buffer $(0.1 \mathrm{~mol} / \mathrm{L}, \mathrm{pH} 7.3)$ for 24 hours. The specimens were postfixed in $1 \%$ osmium tetroxide, dehydrated in acetone, and embedded in Epon fixative. "Green" specimens, 0.5 to $1 \mu \mathrm{m}$ thick, were cut, stained with a polychrome stain, and examined by light microscopy. Corresponding thin sections were cut on an LKB Ultratome III ultramicrotome (LKB Instruments, Inc., Rockville, Md.), mounted on coated copper grids, stained with uranyl acetate and lead citrate, and examined with a Siemens transmission electron microscope (Siemens Corp., Union, N.J.).

Collection and analysis of myocardial function data. Data were collected during each of the measurement periods (before ischemia and at 30 and 60 minutes after unclamping). Three sets of bicaval occlusions were performed at each experimental point, as described previously. ${ }^{1}$ During this period data were collected for 30 seconds on-line with caval occlusion occurring after 5 steady-state cycles and zero stroke work being achieved within 30 sec- onds. All data were filtered by a $50 \mathrm{~Hz}$ low-pass analog filter and digitized in real time by an analog/digital converter with a sampling rate of $200 \mathrm{~Hz}$. The effective sampling interval was 4 msec throughout the cardiac cycle. The data were then recorded on-line by an IBM computer (IBM Corp., Armonk, N.Y.). Laboratory videographic verification of the pressure dimension data was performed before storage.

Data were subsequently analyzed with computer software developed in our laboratory. The method for measuring cardiac function was based on algorithms developed by other investigators using a prolated ellipse model $^{14,15}$ and is briefly described as follows. Cardiac cycles were defined as the rate of first positive pressure rise $(\mathrm{dP} / \mathrm{dt})$ crossing threshold $500 \mathrm{~mm} \mathrm{Hg} / \mathrm{sec}$ after maximum negative $\mathrm{dP} / \mathrm{dt}$. The end-diastolic time was marked as $-40 \mathrm{msec}$ before maximum $\mathrm{dP} / \mathrm{dt}$. Visual plotting of $\mathrm{dP} / \mathrm{dt}$ versus time and pressure-volume loops with end-diastolic time marked confirmed the accuracy of these definitions for each data acquisition interval. The stroke work was determined as the area within the pressure-volume loop by numeric integration, the preload recruitable work area (PRWA). Likewise the LV volume was determined by the formula:

$$
V=\frac{\pi}{6(a-2 h)(b-2 h)^{2}}
$$

where $V=\mathrm{LV}$ internal volume, $a=\mathrm{LV}$ major axis diameter, $b=\mathrm{LV}$ external minor-axis diameter, and $h=$ LV equatorial wall thickness.

Manual review of all cycles in each occlusion was performed to eliminate those with gross tracking errors or electronic artifact. All cardiac cycles with maximum $\mathrm{dP} / \mathrm{dt}$ below $500 \mathrm{~mm} \mathrm{Hg} / \mathrm{sec}$ or stroke work area less than $10 \%$ of the resting steady state were discarded. The stroke work was then automatically regressed against the enddiastolic volume to obtain the slope (M) and $\mathrm{x}$-intercept $\left(\mathrm{V}_{0}, \mathrm{LV}\right.$ end-diastolic volume at zero stroke work) of the 
Volume 109, Number 2

Table III. Elastance results by treatment group

\begin{tabular}{lccc}
\hline & \multicolumn{3}{c}{ Treatment groups } \\
\cline { 2 - 4 } & Group 1 & Group 2 & Group 3 \\
\hline Preclamp slope $\left(\mathrm{erg} \times 10^{3} / \mathrm{ml}\right)$ & $20.9 \pm 5.72$ & $21.7 \pm 2.30$ & $27.7 \pm 6.16$ \\
30 min slope $\left(\mathrm{erg} \times 10^{3} / \mathrm{ml}\right)$ & $9.46 \pm 3.20$ & $10.05 \pm 1.81$ & $16.28 \pm 5.90$ \\
& $(44.7 \%)$ & $(47.4 \%)$ & $(53.6 \%)$ \\
60 min slope $\left(\mathrm{erg} \times 10^{3} / \mathrm{ml}\right)$ & $9.41 \pm 2.71$ & $9.98 \pm 2.10$ & $24.0 \pm 11.92$ \\
& $(45.8 \%)$ & $152.0 \%)$ & $(70.0 \%)$ \\
Preclamp intercept $(\mathrm{ml})$ & $12.9 \pm 2.73$ & $20.8 \pm 4.02$ & $8.25 \pm 2.16$ \\
30 min intercept $(\mathrm{ml})$ & $16.8 \pm 6.12$ & $(169.6 \%)$ & $16.3 \pm 4.21$ \\
& $(165.1 \%)$ & $20.4 \pm 3.82$ & $(226.1 \%)$ \\
60 min intercept $(\mathrm{ml})$ & $23.1 \pm 3.45$ & $(167.8 \%)$ & $15.5 \pm 3.92$ \\
& $(170.2 \%)$ & $(199.6 \%)$ &
\end{tabular}

Values are absolute mean \pm standard error of the mean (percent change of mean from pre-crossclamping control value).

linear preload- and afterload-independent cardiac function curve, termed preload recruitable stroke work (PRSW). ${ }^{16}$ The systolic function was analyzed by computing maximal elastance. ${ }^{17}$ Regression of both PRSW and maximal elastance generated linear relationships with high coefficients greater than 0.90 .

Data were analyzed by repeated-measures analysis of variance performed on absolute numbers with SPSS software (SPSS, Chicago, Ill.), and significance was accepted when the $p$ value was less than 0.05 . Analysis of variance revealed that the experimental design was capable of detecting differences of $12 \%$ or less (power of test $=0.80$; $p=0.05$; two-tailed test).

\section{Results}

Analysis of diastolic function revealed significant improvement of end-diastolic function with amino acid-enhanced cardioplegic solution at 30 minutes as compared with both standard cold and continuous warm cardioplegia (Table II). The amino acid cardioplegia group recovered $69.7 \%$ of its baseline PRSW slope after 30 minutes of reperfusion, whereas the standard cold cardioplegia and warm continuous cardioplegia groups recovered $46.3 \%$ and $49.4 \%$ of baseline slope, respectively $(p<0.05$ for group 2 versus groups 1 and 3). This significant difference, however, was not sustained to 60 minutes of reperfusion, at which time the percent of baseline PRWA slope was $48.9 \%, 60.4 \%$, and $56.4 \%$ for groups 1,2 , and 3, respectively (Table II). Similar results were noted from analysis of PRWA: amino acid cardioplegia provided significantly better function at 30 minutes with $43.4 \%$ recovery of baseline function as compared with $17.7 \%$ for standard cold and $28.1 \%$ for warm continuous cardioplegia. After 60 minutes of unloaded reperfusion, however, no statistically significant difference in recovery of PRWA was measurable among the three groups, with PRWAs of $25.7 \%, 37.1 \%$, and $38.3 \%$, respectively (Table II).
Table IV. Water content of myocardial biopsy tissue after 60 minutes of reperfusion

\begin{tabular}{lccc}
\hline & Group 1 & Group 2 & Group 3 \\
\hline Wet weight $(\mathrm{mg})$ & $1547 \pm 263$ & $1424 \pm 136$ & $1138 \pm 108$ \\
Dry weight (mg) & $408 \pm 56.2$ & $414 \pm 55.0$ & $3376 \pm 66.8$ \\
Percent water content & $81.0 \pm 0.3$ & $79.0 \pm 0.5^{*}$ & $79.8 \pm 0.5$ \\
\hline
\end{tabular}

Values are absolute or percent mean \pm standard error of the mean. ${ }^{*} p<0.05$ by Tukey's multiple range test.

Analysis of elastance data demonstrated slightly better function in the warm continuous cardioplegia group, but this difference did not prove statistically significant. Recovery of elastance at 30 and 60 minutes was $44.7 \%$ and $45.8 \%$ for cold cardioplegia, $47.4 \%$ and $52.0 \%$ for amino acid-enhanced cardioplegia, and $53.6 \%$ and $70.0 \%$ for warm continuous cardioplegia (Table III).

Microscopic and ultrastructural examination of the changes from baseline in the biopsy specimens taken from each animal after 60 minutes of reperfusion showed no qualitative differences among groups. All tissue looked relatively normal, and each group showed only the expected degree of myocyte necrosis, mitochondrial and myofilament abnormalities, cell membrane disruption, and microvascular blockage or wall disruption.

Water content analysis revealed significantly less edema in the amino acid cardioplegia group $(79.0 \%)$ than in the cold cardioplegia group $(81.0 \%)$ at 1 hour after reperfusion (Table IV).

\section{Discussion}

In this study the addition of aspartate and glutamate to resuscitative cardioplegia resulted in a positive but transient effect on LV functional recovery after ischemic injury. The form of ischemic 
injury caused by the experimental methods used here might be characterized as "myocardial stunning" in that a relatively brief period of global ischemia ( 20 minutes) was followed by a period of contractile dysfunction, presumably transient, on reperfusion. ${ }^{18}$ A principal factor in such "stunning" has been reported to be the generation of oxygenderived free radicals on initial reperfusion. ${ }^{19}$

Previous work by other groups has indicated that amino acid substrate enhancement and warm cardioplegia reperfusion improve both metabolic recovery and short-term functional recovery after both regional and global myocardial ischemic injury. ${ }^{3-9}$ It should be noted that numerous differences in design and methods exist between this study and the principal previous experimental study suggesting benefit from amino acid supplementation of resuscitative cardioplegia. ${ }^{7}$ In particular, the earlier study (1) combined 45 minutes of ischemic injury with brief reperfusion as the form of myocardial injury, (2) used antegrade cardioplegia instead of the retrograde cardioplegia used here (the retrograde cardioplegia also had a flow rate high enough possibly to cause some shunting of cardioplegic solution away from the capillary nutritive system), (3) measured the intermittent doses of cardioplegic solution in terms of duration of administration rather than on a body weight basis, and (4) gauged recovery of myocardial function after reperfusion more indirectly by measuring changes in myocardial oxygen uptake and stroke-work index instead of changes in PRWA and maximal elastance.

Despite these differences, however, the earlier investigators noted an improvement in myocardial recovery after 30 minutes of reperfusion in the group receiving amino acid supplementation, as we did. Unfortunately, they did not go on to measure the durability of this improvement beyond $30 \mathrm{~min}$ utes of reperfusion. ${ }^{7}$ In the present study this early improvement in myocardial function noted in the amino acid cardioplegia group had disappeared by the end of 1 hour of unloaded reperfusion. Clearly the results do not demonstrate sustained improvement in LV functional recovery after use of the warm amino acid reperfusion method. This observation is consistent with prior results on regional infarction from our laboratory, which demonstrated no significant additional reduction in final infarct size with amino acid cardioplegia compared with cold blood cardioplegia when these techniques were used as adjuncts to mechanical cardiac unloading. ${ }^{20}$ Furthermore, a terminal cold "washout" dose of standard low-calcium blood cardioplegia may have been equally effective in minimizing oxygen-derived free radical and calcium-induced reperfusion injury.

Dennis and associates ${ }^{21}$ have previously demonstrated that total unloading of the LV reduced myocardial oxygen consumption by $50 \%$, and later application of this technique for an evolving infarction provided substantial reduction in final infarct size. ${ }^{20,22,23}$ The addition of a cardioplegia regimen before controlled, unloaded reperfusion has been shown to have a small, incremental effect on limitation of final infarct size. ${ }^{6,20,24-29}$ Although the addition of amino acids for substrate enhancement and the use of warm blood cardioplegia to optimize enzyme function and oxygen extraction are appealing on a theoretic basis, this approach has not been convincingly shown to significantly reduce infarct size beyond that obtained with unloaded reperfusion in combination with standard cold blood cardioplegia. On the basis of the data in the current study, the warm blood amino acid-enhanced reperfusion method seemed to improve short-term cardiac functional recovery, but the effect was transient. Perhaps the functional improvement seen with the warm amino acid-enhanced resuscitative method would have been more sustained had the duration of controlled reperfusion been longer, as proposed by Allen and colleagues. ${ }^{6}$ This would theoretically allow better repayment of the oxygen debt, with improved function of cells that have had borderline injury.

Nevertheless, the findings of this report are particularly pertinent because both amino acid-enhanced resuscitative cardioplegia and warm continuous cardioplegia techniques have been proposed recently as better clinical alternatives for surgical protection of acutely ischemic myocardium. The results reported here suggest that standard lowcalcium cold blood cardioplegia, used with a final "washout" dose before unclamping and in combination with vented reperfusion, may be equally effectual in minimizing reperfusion injury. Further study is necessary, inasmuch as more complex or costly methods for reperfusing ischemic myocardium during operations cannot be justified unless sustained functional benefits can be clearly demonstrated.

\section{REFERENCES}

1. Crooke GA, Harris LJ, Grossi EA, et al. Role of amino acids and enhancement cardioplegia in routine myocardial protection. J THORAC CARDIOvasc SURG 1993;106:497-501. 
2. Catinella FP, Cunningham JN Jr, Adams PX, Snively SL, Gross RI, Spencer FC. Myocardial protection with cold blood potassium cardioplegia during prolonged aortic cross-clamping. Ann Thorac Surg 1982; 33:228-33.

3. Lazar HL, Buckberg GD, Manganaro AJ, et al. Reversal of ischemic damage with secondary blood cardioplegia. J Thorac Cardiovasc Surg 1979;78: 688-97.

4. Lazar HL, Buckberg GD, Manganaro AJ, Becker H, Maloney JV Jr. Reversal of ischemic damage with amino acid substrate enhancement during reperfusion. Surgery 1980;80:702-9.

5. Rosenkranz ER, Buckberg GD, Laks H, Mulder DG. Warm induction of cardioplegia with glutamate-enriched blood in coronary patients with cardiogenic shock who are dependent on inotropic drugs and intra-aortic balloon support. J THORAC CARDIOVASC SURG 1983;86:507-18.

6. Allen BS, Okamoto F, Buckberg GD, et al. Studies of controlled reperfusion after ischemia. XV. Immediate functional recovery after six hours of regional ischemia by careful control of conditions of reperfusion and composition of reperfusate. J THORAC CARDIOVASC SURG 1986;92:621-35.

7. Rosenkranz ER, Okamoto F, Buckberg GD, Robertson JM, Vinten-Johansen J, Bugyi H. Safety of prolonged aortic clamping with blood cardioplegia. III. Aspartate enrichment of glutamate blood cardioplegia in energy-depleted hearts after ischemic and reperfusion injury. J THORAC CARDIOVASC SuRg 1986; 91:428-35.

8. Lazar HL, Buckberg GD, Manganaro AM, Becker H. Myocardial energy replenishment and reversal of ischemic damage by substrate enhancement of secondary blood cardioplegia with amino acids during reperfusion. J Thorac Cardiovasc Surg 1980;80:350-9.

9. Rosenkranz ER, Vinten-Johansen J, Buckberg GD, Okamoto F, Edwards H, Bugyi H. Benefits of normothermic induction of blood cardioplegia in energydepleted hearts, with maintenance of arrest by multidose cold blood cardioplegic infusions. J THORAC Cardiovasc Surg 1982;84:667-77.

10. Yau TM, Carson S, Weisel RD, et al. The effect of warm heart surgery on postoperative bleeding. $\mathbf{J}$ Thorac Cardiovasc Surg 1992;103:1155-63.

11. Lichtenstein SV, Abel JG, Salerno TA. Warm heart surgery and results of operation for recent myocardial infarction. Ann Thorac Surg 1991;52:455-60.

12. Salerno TA, Houck JP, Barrozo CAM, et al. Retrograde continuous warm blood cardioplegia: a new concept in myocardial protection. Ann Thorac Surg 1991;51:245-7.

13. Lichtenstein SV, Abel JG, Slutsky AS. Warm retrograde cardioplegia. J Thorac Cardiovasc Surg 1992;104:374-80.
14. Glower DD, Spratt JA, Snow ND, et al. Linearity of the Frank-Starling relationship in the intact heart: the concept of preload recruitable stroke work. Circulation 1985;71:994-1009.

15. Morris JJ, Pellom GL, Murphy CE, Salter DR, Goldstein JP, Wechsler AS. Quantification of the contractile response to injury: assessment of the work-length relationship in the intact heart. Circulation 1987;76: 717-27.

16. Glower DD, Spratt JA, Kabas JS, Davis JW, Rankin JS. Quantification of regional myocardial dysfunction after acute ischemic injury. Am J Physiol 1988;255: H85-93.

17. Sagawa K, Maughan L, Suga H, Sunagawa K. Chamber pressure-volume relation versus muscle tensionlength relation. In: Sagawa K, Maughan L, Suga H, Sunagawa K. Cardiac contraction and the pressurevolume relationship. 1st ed. New York: Oxford University Press, 1988:42-109.

18. Braunwald E, Kloner RA. The stunned myocardium: prolonged, postischemic ventricular dysfunction. Circulation 1982;66:1146-9.

19. Bolli R. Mechanism of myocardial stunning. Circulation 1990;82:723-38.

20. Axelrod HI, Galloway AC, Murphy MS, et al. A comparison of methods for limiting myocardial infarct expansion during acute reperfusion-primary role of unloading. Circulation 1987;76(Suppl V):V28-32.

21. Dennis C, Hall DP, Moreno JR, Senning A. Reduction of the oxygen utilization of the heart by left heart bypass. Circ Res 1962;10:298-305.

22. Catinella FR, Cunningham JN, Laschinger JC, Nathan IM, Glassman E, Spencer FC. Significant reduction of infarct size with left atrial to femoral artery bypass. Curr Surg 1983;40:27-9.

23. Grossi EA, Kreiger KH, Cunningham JN, et al. Time course of effective interventional left heart assist for limitation of evolving myocardial infarction. J THORAC Cardiovasc Surg 1986;91:624-9.

24. Vinten-Johansen J, Buckberg GD, Okamoto F, Rosenkranz ER, Bugyi H, Leaf J. Studies of controlled reperfusion after ischemia. V. Superiority of surgical versus medical reperfusion after regional ischemia. J Thorac Cardiovasc Surg 1986;92:52534.

25. Vinten-Johansen J, Rosenkranz ER, Buckberg GD, Leaf J, Bugyi H. Studies of controlled reperfusion after ischemia. VI. Metabolic and histochemical benefits of regional blood cardioplegic reperfusion without cardiopulmonary bypass. J THORAC CARDIOvASC SuRG 1986;92:535-42.

26. Okamoto F, Allen BS, Buckberg GD, et al. Studies of controlled reperfusion after ischemia. VIII. Regional blood cardioplegic reperfusion during total vented bypass without thoracotomy: a new concept. J THOrac Cardiovasc Surg 1986;92:553-63. 
27. Allen BS, Okamoto F, Buckberg GD, Bugyi H, Leaf J. Studies of controlled reperfusion after ischemia. XIII. Reperfusion conditions: critical importance of total ventricular decompression during regional reperfusion. J Thorac Cardiovasc SuRg 1986;92:605-12.

28. Allen BS, Okamoto F, Buckberg GD, et al. Studies of controlled reperfusion after ischemia. IX. Reperfusate composition: benefits of marked hypocalcemia and diltiazem on regional recovery. J THORAC CARDIOVASC SURG 1986;92:564-72.

29. Okamoto F, Allen BS, Buckberg GD, Young H, Bugyi $\mathrm{H}$, Leaf J. Studies of controlled reperfusion after ischemia. XI. Reperfusate composition: interaction of marked hyperglycemia and marked hyperosmolarity in allowing immediate contractile recovery after four hours of regional ischemia. J THORAC CARDIOVASC SURG 1986;92:583-93.

\section{Discussion}

Dr. Davis C. Drinkwater, Jr. (Los Angeles, Calif.). This study is a timely one as the debate continues over which is the optimum cardioplegic composition and administration technique. Focusing as it does on retrograde cardioplegia alone, this report has great potential to further contribute to the literature. However, because of its design, the study is as significant for what it does not show as for what its findings and conclusions actually were. The goal of resuscitation cardioplegia after a preoperative cardiac insult should be to allow the dual purpose of mechanical repair and metabolic correction during the same period of crossclamping. The rationale for integration of all modifications is that the exclusion of one component produces a reduced effectiveness, as indeed this study shows.

Predictably, the first group, that of hypothermic cardioplegia, has the worst overall result because this technique is incapable of repleting any metabolic deficits incurred with a 20-minute global ischemic time.

The poor recovery in the second group with a combination of warm induction and reperfusion with cold intermittent cardioplegia is somewhat perplexing and at variance with our experience and that of others. On closer inspection, one realizes that the protocol in which it was administered differs importantly from previously described techniques using enhanced cardioplegia, in which it was established that the heart requires time to repair itself and replete its metabolic substrate debts. In this study, the maximum resuscitation period of normothermic induction and reperfusion is only $2 \frac{1}{2}$ minutes each for a total protocol dose of $10 \mathrm{ml} / \mathrm{kg}$ per phase. This would achieve only partial and short-lasting recovery. Our previous work shows that 20 minutes is required to replete the significant substrate debts in severely preinjured hearts such as those in cardiogenic shock with acute myocardial infarction. Would the authors consider extending the warm induction and reperfusion phase to be more in line with previously established protocols using modified cardioplegia?

Dr. Grossi. The purpose of using a shorter period of time was to make the overall dosages of amino acids the same. Also, at our institution, volume (with $20 \mathrm{ml} / \mathrm{kg}$ as the initial dose) is the primary criterion rather than time. We believe that the model is clinically relevant and the data speak for themselves.

Dr. Drinkwater. Finally, probably the most significant finding of the study is to further question the benefit of warm continuous cardioplegia as the sole method of inducing and maintaining cardiac arrest during crossclamping. We have previously described, as has more recently the Boston University group, that retrograde cardioplegia alone has a variable and inhomogeneous distribution throughout both the left and right ventricles. Therefore, reliance only on retrograde cardioplegia may certainly cause inadequate distribution of solution to substantial portions of the heart and result in the poor outcome demonstrated in your group 3. Because of the variability of distribution in retrograde route and the need for substrate repletion in preinjured hearts, our routine clinical protocol is a 5-minute induction of warm cardioplegia, with the solution given antegradely and retrogradely to optimize its distribution. We then use cold intermittent cardioplegia to provide maintenance and optimum visualization during the repair, with a final period of warm cardioplegia for at least 5 minutes and up to 20 minutes in those hearts that have had a significant preoperative injury, such as those in cardiogenic shock. With this strategy, the mortality in that very troublesome group has been lowered from the $50 \%$ to $60 \%$ range down to $7 \%$ in our most recent series.

In summary, I agree with the authors' findings, but I am at variance with their conclusions concerning amino acidenhanced cardioplegia based on their protocol. I thank them for pointing out the inadequacy of a nonintegrated cardioplegic technique for myocardial protection and resuscitation. 